\title{
Evaluation of some anthropometric indices for the diagnosis of obesity in pregnancy in Nigeria: a cross-sectional study
}

\author{
Okereke $\mathrm{CE}^{1}$, Anyaehie $\mathrm{UB}^{1}, *$ Dim $\mathrm{CC}^{2}$, Iyare $\mathrm{EE}^{1}$ Nwagha $\mathrm{UI}^{2}$
}

1. Department of Physiology, College of Medicine University of Nigeria Enugu campus (UNEC), Enugu Nigeria

2. Departments of Obstetrics \& Gynaecology/Physiology, College of Medicine UNEC, Enugu Nigeria

\begin{abstract}
Background: Obesity in pregnancy is a global health problem which is associated with poor pregnancy outcomes. The use of weight and height, measured at about ten weeks of gestation, to produce pre-gestational body mass index is recommended for the diagnoses of the condition but limitations abound in under resourced settings.

Objectives: To measure anthropometric indices such as mid upper arm circumference, calf circumference, waist circumference and waist to hip ratio, for identification of obesity in pregnancy.

Methods: Anthropometric measurements were carried out on cohorts of pregnant women from 4 hospitals in Enugu, South-eastern Nigeria.

Results: There were no significant difference in the mean mid upper arm circumference (MUAC) and calf circumference (CC) across the trimester groups. The mean values of waist circumferences, hip circumference and waist to hip ratios changed significantly across the trimesters. The $75^{\text {th }}$ percentile of MUAC $(33 \mathrm{~cm})$ and CC $(39 \mathrm{~cm})$ in all trimesters, had sensitivity and specificity of more than $70 \%$ for identifying obesity in pregnancy.

Conclusion: MUAC and CC values of $33 \mathrm{~cm}$ and $39 \mathrm{~cm}$ respectively might be reliable cut off points for diagnoses of obesity throughout pregnancy in Enugu, Nigeria

Key words: Anthropometric indices, Body mass index, obesity, oregnancy, Nigeria

African Health Sciences 2013; 13(4): 1034 - 1040 http://dx.doi.org/10.4314/ahs.v13i4.25
\end{abstract}

\section{Introduction}

The accumulation of excessive body fat otherwise referred to as obesity, is a major risk factor for poor pregnancy outcome. ${ }^{1,2}$ It is most commonly classified using the Body Mass Index (BMI) which is defined as person's weight in kilograms divided by the square of the height in meters $\left(\mathrm{kg} / \mathrm{m}^{2}\right)$ - a BMI of $30 \mathrm{~kg} /$ $\mathrm{m}^{2}$ or greater is considered as obesity for both pregnant and non pregnant populations. ${ }^{1,2}$ In pregnancy, a pre-pregnancy BMI or that calculated at initial booking visit (by 10 weeks of gestation) is used for the diagnosis of obesity in pregnancy. ${ }^{2}$ Furthermore, three classes of obesity have been identified thus: Class 1 (BMI 30.0-34.9) ; Class 2

\section{*Corresponding author:}

Dr. Cyril C. Dim

Departments of Obstetrics \& Gynaecology

Faculty of Medical Sciences

College of Medicine, University of Nigeria Enugu campus

P.M.B. 01129, Enugu. 400001.

Nigeria

E-mail: cyril.dim@unn.edu.ng
(BMI 35.0-39.9); and Class 3 or morbid obesity (BMI 40 and over). ${ }^{3,4,5}$ Prevalence of obesity in pregnancy has been on the increase in both developed and developing countries, ${ }^{5-8}$ and Nigeria may not be an exception.

A report from Tanzania showed that the incidence of obesity among antenatal women had increased from $3.6 \%$ in 1995 to $9.1 \%$ in $2004 .{ }^{6 .}$ In England, obesity in pregnancy has increased from around $10 \%$ in the early 1990 s to $16-19 \%$ in the 2000s. ${ }^{7}$ Likewise, in the United States of America, the prevalence of maternal obesity ranges from $18.5 \%$ to $38.3 \% .^{1,8}$ In Nigeria, a prevalence of $7.7 \%$ was reported from a hospital based study in Abakiliki, Ebonyi state. ${ }^{9}$ Obesity in pregnancy is associated with many adverse effects including maternal deaths. ${ }^{10,11}$ Other complications include preeclampsia, gestational hypertension, gestational diabetes, sleep apnoea, non alcoholic fatty liver disease, intrauterine death, increased risk for caesarean operation, increased post operative complication such as infection, haemorrhage and deep vein thrombosis, increased urinary symptoms such as stress incontinence and urgency. ${ }^{1,9,11-16}$ Furthermore, the 
effects on fetal outcome include macrosomia with its associated risks, increased childhood obesity, hypertension, diabetes and metabolic syndrome. ${ }^{17}$

Traditionally, BMI is used to classify pregnant women as underweight, normal, overweight, or obese. It is recommended that this index be calculated for all women using appropriate measurements, during the initial booking visit at about 10 weeks of gestation. ${ }^{18}$ Nevertheless, the use of BMI in identifying obesity in pregnancy may not be a sensitive and specific criterion because of the additional weight gain due to the presence of the fetus and placenta, as well as the increase in size of maternal organs especially the breasts and the uterus. ${ }^{19}$ Also, there may be accumulation of fluid in the extra cellular spaces in pregnancy which would increase the maternal weight. ${ }^{19}$ On the other hand, the lordosis which occurs in pregnancy may be associated with a decrease in height of the woman. ${ }^{20,21}$ Furthermore, an increase in height of the adolescent pregnant women is a possibility. ${ }^{20}$ Most importantly, very few women register for antenatal care at about 10 weeks of gestation, even in developed countries. ${ }^{7}$ The average gestational age at booking in the study area was 26 weeks. ${ }^{22}$ These considerations might have influenced the use of absolute weight of $90 \mathrm{~kg}$ and above, at any period during pregnancy, as the definition of obesity in pregnancy in our environment. ${ }^{23,24}$ However, the reliability of this assumption calls for further studies.

It is obvious that the appropriate management of maternal obesity can only be possible with a consistent and reliable identification of those women who are at risk. ${ }^{1}$ In view of the short comings of BMI stated above, it is important to identify reliable alternatives. This study assessed the use of Mid Upper Arm circumference (MUAC), Hip circumference (HC), Waist circumference (WC), and Calf circumferences (CC) as low cost measures of obesity in pregnancy. These measures avoided the use of mathematical calculations, sophisticated equipments, and regular equipment standardization which are important considerations in under-resourced settings.

\section{Methods}

This was a cross-sectional study of 578 consecutive consenting pregnant women receiving pre-natal care in 4 hospitals located at different areas in Enugu metropolis, Enugu state, Nigeria. Enugu town is the capital of Enugu state which is one of the five states in the predominantly Igbo speaking Southeast geopolitical zone of Nigeria. A summary description of the Enugu state of Nigeria has been described in a recent report. ${ }^{25}$ The study centers included University of Nigeria Teaching Hospital (UNTH) Enugu (government specialist hospital); Mother of Christ Specialist Hospital, Enugu (Mission specialist hospital); St. Patricks Specialist Hospital and Maternity Enugu (Private specialist hospital); and Colliery Hospital Enugu (government general hospital).The hospitals were selected purposively based on their capacity to offer comprehensive emergency obstetric services and antenatal care to women from all socio-economic classes. The study was conducted over three month period of September to November 2011.

All consenting healthy pregnant women receiving care at the selected hospitals within the study period were eligible for the study. Exclusion criteria included unsure of date of last menstruation, multiple pregnancies, leg edema up to mid-shin, and medical diseases in pregnancy such as diabetes mellitus and HIV infection. Study participants were categorized into three groups (trimesters) according to the age of the pregnancy in weeks. Each participant's age, parity, and gestational age were recorded in a proforma prepared for the study.

Participant's weight and height were measured with a standardized T160 Health Scale (Techmel \&Techmel USA) in a private room, while the woman was minimally dressed and without foot wears. Participants' weights and heights were measured to the nearest $0.5 \mathrm{~kg}$ and 0.1 meter respectively; and their BMI were calculated as described in the introduction. Subsequent measurements were made to the nearest millimetre or centimetre using two surfaced non-stretchable tape - one surface was graduated in centimetres while the other was in inches. During the measurements, the centimetre surface was facing down to minimise observer bias. Mid arm circumference was measured at the midpoint between the acromion process and the olecranon process of the humerus with the upper limbs hanging loosely by the participant's side. Calf circumference was measured at the point of widest diameter of the calf while participants were standing. Each of these measurements was carried out on the left limb of the participants.

Waist circumference was measured by identifying the upper border of the hip bone and placing the tape around the subject at that level and the level of the navel. Hip circumference was measured at the widest portion of the gluteal region. Waist to hip $(\mathrm{W} / \mathrm{H})$ ratio was calculated by dividing the waist circumference by the Hip circumference. For each study participant, each anthropometric parameter was measured twice and the mean value recorded. The measurements were carried out between 0900 to 1200 hours, by trained assistants (midwives) blinded to the study objectives. 
Data analyses were both descriptive and inferential using SPSS software version 15 . The frequency command of the descriptive statistics was used to determine percentiles while associations were compared using ANOVA and Pearson's correlation coefficient as appropriate. A p - value of less than 0.05 (ANOVA) or 0.01 (correlation co-efficient) was considered significant.

For the purpose of this study, first trimester ends at 13 weeks of gestation from the first day of the last menstrual period, second trimester - 14 to 27 weeks, while third trimester extends from 28 to 40 weeks of gestation.

The estimated weight gain (EWG) in kilograms was derived by subtracting 10 from each participant's gestational age (GA) and multiplying the difference by 0.44 . This was based on a study from Nigeria which reported that the mean maternal weight gain, from 10 weeks to 40 weeks of gestation, was $13.3 \mathrm{~kg}$, ${ }^{26}$ (which translated to an average of $0.44 \mathrm{~kg}$ per week). The estimated maternal weight at 10 weeks gestation was therefore derived by subtracting the EWG from her measured weight. Furthermore, because BMI calculated by 10 weeks of gestation could be used for the diagnosis of obesity in pregnancy, ${ }^{2}$ this study assumed that estimated weight at 10 weeks gestation was equivalent to pre-pregnancy maternal weight.
The study was approved by Ethical Committee of the UNTH, Enugu, Nigeria.

\section{Results}

Five hundred and seventy eight women participated in the study and were stratified into three cohorts (trimesters) according to their gestational age thus: 143 women $(24.8 \%)$ were in their first trimester of pregnancy, $206(35.6 \%)$ in second trimester, and 229 $(39.6 \%)$ in third trimester. The mean age of study participants was $28.5 \pm 4.5$ years. (range $=15-40$ ). There was no significant difference in participants' mean age across the trimester groups $(p=0.32)$. A majority $(47.1 \%)$ of the study participants were nulliparous, $267(46.2 \%)$ were multiparous, while the remaining $6.8 \%$ were grand-multiparous. The participants' mean heights were comparable across the three groups $(p=0.41)$. The mean values of participants' weight, BMI, and WC increased significantly from the first trimester to the third trimester, while those of MUAC and CC did not vary significantly across the three groups $(\mathrm{P}=0.74,0.75$ respectively). The $25^{\text {th }}$ and $75^{\text {th }}$ percentiles for BMI in the first trimester group were $23.3 \mathrm{~kg} / \mathrm{m}^{2}$ and 30.9 $\mathrm{kg} / \mathrm{m}^{2}$ respectively. Details of the distribution and relationship of participants' anthropometric indices across the trimester groups are shown in table 1.

Table 1: Distribution of participants' anthropometric variables across the trimester groups

\begin{tabular}{llllll}
\hline Variable & Measures & $\begin{array}{l}\mathbf{1}^{\text {st }} \text { trimester } \\
(\mathbf{n}=\mathbf{1 4 3})\end{array}$ & $\begin{array}{l}\mathbf{2}^{\text {nd }} \\
(\mathbf{n}=\mathbf{2 0 6})\end{array}$ & $\begin{array}{l}\mathbf{3}^{\text {rd }} \text { trimester } \\
(\mathbf{n}=\mathbf{2 2 9})\end{array}$ & $\mathbf{P}$ - value \\
\hline BMI $\left(\mathrm{kg} / \mathrm{m}^{2}\right)$ & Mean $\pm \mathrm{SD}$ & $27.72 \pm 4.98$ & $28.71 \pm 4.44$ & $30.72 \pm 4.80$ & 0.001 \\
& $25^{\text {th }}$ percentile & 23.30 & 25.44 & 27.00 & - \\
& $75^{\text {th }}$ percentile & 30.99 & 31.46 & 33.90 & - \\
MUAC $(\mathrm{cm})$ & Mean $\pm \mathrm{SD}$ & $30.47 \pm 3.88$ & $30.23 \pm 4.03$ & $30.15 \pm 3.85$ & 0.74 \\
& $25^{\text {th }}$ percentile & 27.00 & 27.00 & 27.00 & - \\
& $75^{\text {th }}$ percentile & 33.00 & 33.00 & 33.00 & - \\
CC $(\mathrm{cm})$ & Mean $\pm \mathrm{SD}$ & $36.81 \pm 3.49$ & $36.81 \pm 3.49$ & $37.06 \pm 3.81$ & 0.75 \\
& $25^{\text {th }}$ percentile & 34.00 & 34.00 & 35.00 & - \\
& $75^{\text {th }}$ percentile & 39.00 & 39.00 & 40.00 & - \\
WC $(\mathrm{cm})$ & Mean $\pm \mathrm{SD}$ & $92.06 \pm 10.28$ & $97.57 \pm 10.78$ & $106.46 \pm 12.00$ & 0.001 \\
& $25^{\text {th }}$ percentile & 83.00 & 89.00 & 99.00 & - \\
& $75^{\text {th }}$ percentile & 97.50 & 104.00 & 114.00 & - \\
HC $(\mathrm{cm})$ & Mean $\pm \mathrm{SD}$ & $105.31 \pm 9.10$ & $105.97 \pm 8.79$ & $108.65 \pm 9.27$ & 0.001 \\
& $25^{\text {th }}$ percentile & 96.00 & 100.00 & 101.00 & - \\
& $75^{\text {th }}$ percentile & 110.50 & 112.00 & 115.00 & - \\
W $/$ Hip ratio & Mean $\pm S D$ & $0.87 \pm 0.05$ & $0.92 \pm 0.06$ & $0.98 \pm 0.08$ & 0.001 \\
& $25^{\text {th }}$ percentile & 0.83 & 0.88 & 0.95 & - \\
& $75^{\text {th }}$ percentile & 0.90 & 0.96 & 1.02 & - \\
\hline
\end{tabular}


Participants' MUAC, CC, WC, and WC had significant strong positive correlation with their BMI. The $75^{\text {th }}$ percentiles for the parameters (i.e. MUAC, and CC) that correlated strongly with BMI but did not vary across the trimester were $33 \mathrm{~cm}$ and $39 \mathrm{~cm}$ respectively. Details of correlation of the anthropometric parameters with BMI are shown in table 2.

Using estimated pre-pregnancy BMI of 30 as the gold standard for obesity and the $75^{\text {th }}$ percentile of MUAC and CC as cut off points for obesity, the sensitivity, specificity, positive and negative predicative values of MUAC and CC for the determination of obesity in pregnancy were calculated. MUAC had a sensitivity and specificity of $76 \%$ and $91 \%$ respectively, while CC had a sensitivity and specificity of $78 \%$ and $85 \%$ respectively. Details of the predictive values of these parameters are shown in the table 3.

Table 2: Correlations of Anthropometric Parameters with BMI

\begin{tabular}{llllllll}
\hline Variables & & BMI & MUAC & CC & WC & HC & W/Hip ratio \\
\hline $\begin{array}{l}\text { BMI }\left(\mathrm{kg} / \mathrm{m}^{2}\right) \\
\mathrm{n}=578\end{array}$ & $\begin{array}{l}\text { Correlation } \\
\text { coefficient } \\
\text { P value }\end{array}$ & 1.00 & 0.87 & 0.77 & 0.87 & 0.88 & 0.36 \\
\hline
\end{tabular}

${ }^{a}$ Level of significance set at $\mathrm{P}<0.001$

Table 3: Specificity, Sensitivity, and Predictive values of MUAC and CC

\begin{tabular}{|c|c|c|c|c|}
\hline Sensitivity (\%) [TP / & MUAC & True positive (TP) & 123 & $76 \%$ \\
\hline$(\mathrm{TP}+\mathrm{FN})] \times 100$ & & False Negative (FN) & 39 & \\
\hline & CC & TP & 130 & $78 \%$ \\
\hline & & FN & 36 & \\
\hline Specificity $(\%)[T N$ & MUAC & True negative (TN) & 378 & $91 \%$ \\
\hline$/(\mathrm{FP}+\mathrm{TN})] \times 100$ & & False positive (FP) & 38 & \\
\hline & $\mathrm{CC}$ & $\mathrm{TN}$ & 349 & $85 \%$ \\
\hline & & FP & 63 & \\
\hline+ ve predictive value & MUAC & $\mathrm{TP}$ & 123 & $76 \%$ \\
\hline$[\mathrm{TP} /(\mathrm{TP}+\mathrm{FP})] \times 100$ & & FP & 38 & \\
\hline & $\mathrm{CC}$ & TP & 130 & $67 \%$ \\
\hline & & FP & 63 & \\
\hline -ve predictive value & MUAC & $\mathrm{TN}$ & 378 & $91 \%$ \\
\hline$[\mathrm{TN} /(\mathrm{FN}+\mathrm{TN})] \times 100$ & & $\mathrm{FN}$ & 39 & \\
\hline & $\mathrm{CC}$ & TN & 349 & $91 \%$ \\
\hline & & $\mathrm{FN}$ & 36 & \\
\hline Prevalence of obesity in & MUAC & TP & 123 & $28.0 \%$ \\
\hline pregnancy $[(\mathrm{TP}+\mathrm{FN}) / \mathrm{n}] \times 100$ & & $\mathrm{FN}$ & 39 & \\
\hline & $\mathrm{CC}$ & $\mathrm{TP}$ & 130 & $28.7 \%$ \\
\hline & & $\mathrm{FN}$ & 36 & \\
\hline
\end{tabular}

\section{Discussion}

Anthropometric measurements taken during antenatal period have been used to predict increased risk of gestational diabetes, preeclampsia, eclampsia, fetal macrosomia, post-term delivery, and caesarean section which are associated with obesity in pregnancy. ${ }^{27,28}$ In this study, pregnant women living in Enugu were studied to ascertain how these parameters could be used to identify obese pregnant women in our environment.

African Health Sciences Vol 13 Issue 4 December 2013
From this study the mean BMI increased significantly from the first to third trimester (table 1). This is because participants' mean height remained unchanged while the mean weight increased progressively across the trimesters due to the reasons described in the introduction; including the increase in size of maternal uterus and other organs as well as weight of the fetus and placenta. ${ }^{19}$ It is therefore 
obvious that BMI is not a specific index for identifying obesity throughout pregnancy because women's weight increased as gestational age increased while height remained constant. This may explain the use of pre-pregnancy BMI or that around 10 weeks of gestation for the definition of obesity in pregnancy. ${ }^{2}$ However, in our environment where women are neither aware of their pre-pregnancy weight nor book early in pregnancy, MUAC and CC which were not affected by pregnancy in this study, could be promising indices for identifying obesity in pregnancy. According this study, MUAC seemed to be a better test than CC, for the screening of obesity throughout pregnancy, considering its higher sensitivity and specificity (table 3). Likewise, MUAC might also be more clinically relevant than CC for the screening of obesity in pregnancy because it produced higher predictive values at about the same disease prevalence. Nevertheless, further study, devoid of the assumptions and limitations noted below, is proposed to compare the accuracy of MAUC and CC for screening of obesity in pregnancy.

MUAC from our study has strong positive correlations with maternal weight (BMI) but there was no significant difference in the three trimester groups which suggests that MUAC is independent of gestational age and could be used to identify obesity in women regardless of the age of pregnancy. This finding agreed with reports from previous studies. ${ }^{29,30}$

Furthermore, this study also showed that CC correlated with BMI but the association was not as strong as that of as MUAC, which is consistent with the reports by Khadivzadeh and co-workers. ${ }^{31}$ On the other hand, CC did not vary significantly across the 3 trimester groups in this study which is contrary to the findings of a longitudinal study in Columbia that showed a significant difference in calf circumferences between the second and third trimester groups of women. ${ }^{32}$ It was likely that their study participants developed edema later in pregnancy unlike in our study where women who had edema up to the mid-shin were excluded from the study. This study therefore suggests that calf circumference may be a pointer to the pre-pregnancy weight of the woman in our environment in the absence of leg oedema. Waist circumference and waist to hip ratio are measures of central adiposity used to predict adverse pregnancy outcomes. Various studies have tried to assign cut off points of waist circumference for preeclampsia, gestational diabetes and dislipidaemia. ${ }^{27,33}$ In our study, mean waist circumference increased significantly from first to second trimester, contrary to the study by Wendland and co-workers which showed that waist circumference did not increase significantly until 28 weeks of gestation. ${ }^{27}$ Though waist circumference correlated positively with BMI in this study, it increased across the trimesters; so, in order to use WC to identify obesity in pregnancy in our environment, different cut off may be needed for different ranges of gestational age. This consideration also goes for $\mathrm{HC}$ which was found to increase significantly across the trimesters in this study.

Hip circumference which has been known to be inversely related to adverse effects of obesity, ${ }^{32}$ was also seen to vary significantly across the trimester groups. It was found that women who had an increase in hip circumference gave birth to normal birth weight neonates while reduction or static hip circumference was associated with low birth weight. ${ }^{32}$ In our study, waist circumference increased more than hip circumference hence the increase in mean $\mathrm{W} / \mathrm{H}$ ratio. Like the $\mathrm{WC}, \mathrm{W} / \mathrm{H}$ ratio may be useful in the identification of obesity in pregnancy in our environment, if different cut offs points are set for different trimesters.

This study estimated the maternal weight at 10 weeks of gestation; and because BMI calculated by 10 weeks of gestation could be used for the diagnosis of obesity in pregnancy, ${ }^{2}$ the estimated weight was also assumed to be equivalent to the maternal pre-pregnancy weight. These limitations were inevitable since most pregnancies in the study environment were unplanned,,$^{34}$ and the awareness of pre-pregnancy weight was an exception. Likewise, pregnant women in the study area do not book early for antenatal care so, their actual weights at 10 weeks of gestation were not available. The assumptions noted above could have introduced measurement bias into the study but its effects on the study estimated were likely to be minimal and nondifferential.

\section{Conclusion}

Obesity impacts negatively on the progress and outcome of pregnancy, therefore the need for a reliable measure cannot be overemphasized. Our study has shown that MUAC and CC values of 33 $\mathrm{cm}$ and $39 \mathrm{~cm}$ respectively might be reliable cut off points for diagnosis of obesity throughout pregnancy in our environment. This finding is remarkable because the study area is characterized by 
undeveloped preconception care and late antenatal booking which makes the awareness of prepregnancy or maternal weight at 10 weeks of gestation almost impossible to women. Nevertheless, a population study would be necessary to validate this study's results.

\section{Acknowledgement}

Authors acknowledge all management of all study centers used for the study.

\section{References}

1. Galtier-Dereure F, Boegner C, Bringer J. Obesity and pregnancy: Complications and Cost. Am J Clin Nutr. 2000.71 (5 Suppl):1242S - 8S.

2. Modder J, Fitzsimons KJ. Centre for Maternal and Child Enquiries (CMACE) / Royal College of Obstetricians and Gynaecologists (RCOG) Joint Guideline: Management of Women with Obesity in Pregnancy. 2010 [http://www.oaaanaes.ac.uk/assets/_managed/editor/File/ $\mathrm{R}$ e p ort s/ 2010 - C M A C E RCOG_guideline_obesity_in_pregnancy.pdf]

3. National Institute for Health and Clinical Excellence. Obesity: Guidance on the prevention, identification, assessment and management of overweight and obesity in adults and children. 2006. [http://www.nice.org.uk/nicemedia/pdf/ CG43FullGuideline1.pdf]

4. World Health Organization. Obesity: Preventing and managing the global epidemic. WHO Technical Report Series 894, 2000. [http:// whqlibdoc.who.int/trs/WHO_TRS_894.pdf]

5. Johnson JW, Longmate JA, Frentzen B. Excessive maternal weight and pregnancy outcome. Am J Obstet Gynecol. 1992; 167 (2): 353 - 70.

6. Villamor E, Msamanga G, Urassa W, Petraro P, Spiegelman D, Hunter DJ, et al. Trends in obesity, underweight, and wasting among women attending Prenatal clinics in Urban Tanzania, 19952004. Am J Clin Nutr. 2006; 83 (6): 1387-94.

7. Heslehurst N, Lang R, Rankin J. Wilkinson JR, Summerbell CD. Obesity in pregnancy: a study of the impact of maternal obesity on NHS maternity services. BJOG. 2007; 114 (3): 334-42.

8. Kanagalingam MG, Forouhi NG, Greer IA, Sattar N. Changes in booking body mass index over a decade: Retrospective analysis from a Glasgow Maternity Hospital. BJOG 2005; 112 (10): 1431-3.
9. Obi SN, Obute EA. Pregnancy Outcome in the Obese Nigerian. Trop J Obstet Gynaecol 2004; 21 (1): $32-5$

10. Lewis $G(E d)$. The Confidential Enquiry into Maternal and Child Health (CEMACH). Saving Mothers' Lives: reviewing Maternal deaths to make motherhood safer - 2003-2005. The Seventh Report on Confidential Enquiries into Maternal deaths in United Kingdom. London: CEMACH. 2007

11. Sebire NJ, Jolly M, Harris JP, Wadsworth J, Joffe M, Beard RW, et al. Maternal obesity and pregnancy outcome: a study of 287,213 pregnancies in London. Int $J$ Obes Relat Metab Disord 2001; 25 (8): 1175-82.

12. Odell LD, Mengert WF. The Overweight Obstetric patient. JAMA. 1945; 128 (2): 87-90.

13. Gross T, Sokol RJ, King KC. Obesity in pregnancy: risks and outcome. Obste Gynecol.1980; 56 (4): 446-50.

14. Calandra C, Abell DA, Beischer NA. Maternal obesity in pregnancy. Obstet Gynecol. 1981; 57 (1): 8-12.

15. Johnson SR, Kolberg BH, Varner MW, Railsback LD. Maternal obesity and pregnancy. Surg, Gynecol Obstet. 1987; 164 (5): 431-7.

16. Garbaciak JA, Richter M, Miller S, Barton JJ. Maternal weight and pregnancy complications. Am J Obstet Gynecol.1985; 152 (2): 238-45.

17. Palti H, Rothschild E. Blood pressure and growth at 6 years of age among offspring of mothers with hypertension of pregnancy. Early Hum Dev.1989; 19 (4): 263-9.

18. National Institute for Health and Clinical Excellence. Antenatal care: Routine care for the healthy pregnant woman. RCOG, London. 2008

19. Campbell S, Lees C. (eds). Obstetrics by Ten Teachers. 7th edn. Arnold. London. 2000

20. Scholl TO, Hediger ML, Ances IG. Maternal Growth during Pregnancy and decreased infant birth weight. Am J Clin Nutr. 1990; 51 (5): 790-3.

21. Hirabayashi Y,Shimizu R, Fukuda H, Saitoh K, Furuse M. Anatomical configuration of the supine position. II. Comparison of pregnant and non-pregnant women. BrJ Anasth. 1995; 75 (1): 6-8.

22. Nwagha UI, Ugwu OV, Nwagha TU, Anyaehie US. The influence of parity on the gestational age at booking among pregnant women in Enugu, South East Nigeria. Niger J Physiol Sci. 2008; 23 (1-2): 67-70. 
23. Olayemi OO, Umuerri CO, Aimakhu CO. Obstetric Performance of Nigerian Obese Parturients. Trop J Obstet Gynaecol 2002; 19 (1): 17 $-20$

24. Klufio CA. Obesity in Pregnancy. In: Kwawukume EY, and Emuveyan EE (eds) Comprehensive Obstetrics in the Tropics. Dansoman: Asante \& Hittscher Printing Press Ltd; 2002: $219-25$

25. Dim CC, Ikeme AC, Ezegwui HU, Nwagha UI. Labor support: an overlooked maternal health need in Enugu, south-eastern Nigeria. J Matern Fetal Neonatal Med. 2011; 24 (3): 471-4

26. Lawoyin TO. Maternal weight and weight gain in Africans. Its relationship to birth weight. J Trop Pediatr 1991; 37 (4): 166-71

27. Wendland EM, Duncan BB, Mengue SS, Nucci LB, Schmidt MI. Waist circumference in the prediction of obesity-related adverse pregnancy outcomes. Cad Saude Publica. 2007; 23 (2): 391-8.

28. Satter N, Clark P, Holmes A, Lean ME, Walker I, Greer IA. Antenatal Waist Circumference and Hypertension Risk. Obstet Gynecol. 2001; .97 (2): 267-71.

29. Krasovec K. An investigation into the use of maternal arm circumference for nutritional monitoring of pregnant women. Baltimore, 1989 (SC. D. Dissertation - Johns Hopkins University/ School of Hygiene and Public Health)

30. Ricalde AE, Velasques-Melendez G, Tanaka AC. de Siqueira AA. Mid upper arm circumference in pregnant women and its relationship to birth weight. Rev Saude Publica. 1998; 32 (2): 112-7.

31. Khadivzadeh T. Mid upper arm and calf circumferences as indicators of nutritional status in women of reproductive Age. East Mediterr Health J. 2002; 8 (4-5): 612 - 8

32. Piperata BA, Dufour DL, Reina JC, Spurr GB. Anthropometric characteristics of pregnant women in Cali, Colombia and relationship to birth weight. Am J Hum Biol. 2002; 14 (1): 29-38

33. Yamamoto S, Douchi T, Yoshimitsu N, Nakae M, Nagata Y. Waist to hip circumference ratio as a significant predictor of preeclampsia, irrespective of overall adiposity. J Obstet Gynaecol Res. 2001; 27 (1): 27-31

34. Ezegwui HU, Dim CC, Dim NR, Ikeme ACC. Preconception care in South Eastern Nigeria. J Obstet Gynaecol 2008; 28 (8): 765 - 68 